IIIIIIIIIIIIIIIIIIIIIIIIIIIIIIIIIIII

Original Article

IIIIIIIIIIIIIIIIIIIIIIIIIIIIIIIIIII

\title{
Isolation of isolactarane sesquiterpenes from a Phlebia tremellosa culture filtrate and their growth promotion effects on lettuce roots
}

\author{
Atsushi Ishinara, ${ }^{1, *}$ Chisaki Ashida, ${ }^{1}$ Naoki Ube, ${ }^{2}$ Masato Abe, ${ }^{3}$ Hidetaka Hiyoshi, ${ }^{4}$ \\ Kazuto Umezu, ${ }^{4}$ Naoki Endo, ${ }^{1}$ Kozue Sotome, ${ }^{1}$ Nitaro Maekawa, ${ }^{1}$ Akira Nakagiri, ${ }^{1}$ \\ Kumiko Osaki-Oka, ${ }^{1}$ Tsuyoshi Ichiyanagi ${ }^{1}$ and Kotomi Ueno ${ }^{1}$ \\ ${ }^{1}$ Faculty of Agriculture, Tottori University, Tottori 680-8553, Japan \\ ${ }^{2}$ The United Graduate School of Agricultural Sciences, Tottori University, Tottori 680-8553, Japan \\ ${ }^{3}$ Faculty of Agriculture, Ehime University, Matsuyama 790-8566, Japan \\ ${ }^{4}$ Kumiai Chemical Industry, Co., Ltd., Tokyo 110-8782, Japan
}

(Received August 28, 2018; Accepted November 7, 2018)

\begin{abstract}
The ethyl acetate extract of the culture filtrate of Phlebia tremellosa promoted elongation of the lateral roots of lettuce seedlings at $250 \mu \mathrm{g} / \mathrm{mL}$. We purified two compounds that promote root elongation by using activity-guided chromatographic fractionation. On the basis of spectroscopic analyses, these compounds were identified to be isolactarane sesquiterpenes derived from the dehydrogenation of merulactone, which was previously isolated from the same species. We named the purified compounds phlelactones A and B. Phlelactones A and B promoted primary root elongation at $100-300$ and $10-30 \mu \mathrm{g} / \mathrm{mL}$ and the elongation and formation of lateral roots at 300-1000 and 30-100 $\mathrm{g} / \mathrm{mL}$, respectively. ㅇ Pesticide Science Society of Japan

Keywords: Phlebia tremellosa, plant growth regulator, root development, isolactarane, phlelactone.

Electronic supplementary material: The online version of this article contains supplementary material (Supplemental Tables S1 and S2, and Supplemental Figs. S1-S5), which is available at http://www.jstage.jst.go.jp/browse/jpestics/
\end{abstract}

\section{Introduction}

Plant growth regulators are compounds with biological activities such as the promotion of plant growth, acceleration of maturation, stimulation of fruit coloration and enhancement of tolerance to biological and environmental stresses. Plant growth regulators have attracted increasing attention because of concerns regarding the adverse effects of global climate change on crop production. Various substances including plant hormones, inorganic compounds, extracts from plants, fermentation products, and synthetic chemicals, have been shown to have these activities, and categorized as plant growth regulators. ${ }^{1,2)}$

Mushrooms are fungal species that form visible fruiting bodies and are considered valuable sources of novel bioactive compounds. The Fungus/Mushroom Resource and Research Center (FMRC) at Tottori University has collected and maintained 8,387 mushroom strains belonging to 1,400 species (as of March 2017), which form one of the largest mushroom culture collections in the world. We have made an extract library of the mushrooms. Using this library, we initiated an investigation of the

\footnotetext{
* To whom correspondence should be addressed.

E-mail: aishihara@tottori-u.ac.jp

Published online December 27, 2018

(C) Pesticide Science Society of Japan
}

bioactive compounds present in these strains and have identified several antimicrobial compounds ${ }^{3,4)}$ and new tyrosinase inhibitors. ${ }^{5)}$ These findings strongly suggested that there remain many opportunities to discover new specialized metabolites with biological activity in mushrooms.

Recently, compounds with plant growth-promoting and -suppressing activities were isolated from mushroom cultures. Some mushroom species have been known to form a circular arrangement of fruiting bodies called "fairly rings" on grasslands and to promote or suppress the growth of surrounding grasses. ${ }^{6}$ ) From the culture filtrate of the fairy-ring-forming mushroom Lepista sordida (Schumach.) Singer, 2-azahypoxanthine (AHX) and imidazole-4-carboxyamide (ICA) have been isolated, and they showed plant growth-promoting and -suppressing activities, respectively. ${ }^{7,8)}$ The application of these compounds, which have been referred to as "fairy compounds," yields of rice ${ }^{10)}$ and wheat ${ }^{11)}$ in the field.

On the basis of these findings, we screened extracts derived from the fruiting bodies and liquid cultures of FMRC-preserved mushroom strains in an attempt to identify novel plant growth regulators. Hymexazol (3-hydroxy-5-methylisoxazole) and isoprothiolane (diisopropyl 1,3-dithiolane-2-ylidenemalonate), which are known plant growth regulators that increase the yield of rice, have also been shown to promote root development. ${ }^{12,13)}$ Thus, we have focused on their promotion of root development 
Table 1. ${ }^{1} \mathrm{H}(600 \mathrm{MHz})$ and ${ }^{13} \mathrm{C} \mathrm{NMR}(150 \mathrm{MHz})$ data of $\mathbf{1}, \mathbf{2}$ and merulactone in $\mathrm{CDCl}_{3}$.

\begin{tabular}{|c|c|c|c|c|c|c|}
\hline \multirow[b]{2}{*}{ Position } & \multicolumn{2}{|l|}{1} & \multicolumn{2}{|l|}{2} & \multicolumn{2}{|c|}{ Merulactone $^{a)}$} \\
\hline & $\begin{array}{c}\delta_{\mathrm{H}} \\
\mathrm{ppm}\end{array}$ & $\begin{array}{c}\delta_{\mathrm{C}} \\
\mathrm{ppm}\end{array}$ & $\begin{array}{c}\delta_{\mathrm{H}} \\
\mathrm{ppm}\end{array}$ & $\begin{array}{c}\delta_{\mathrm{C}} \\
\mathrm{ppm}\end{array}$ & $\begin{array}{c}\delta_{\mathrm{H}} \\
\mathrm{ppm}\end{array}$ & $\begin{array}{c}\delta_{\mathrm{C}} \\
\mathrm{ppm}\end{array}$ \\
\hline \multirow[t]{2}{*}{1} & $4.09 ; \mathrm{s}$ & 80.5 & $4.11 ; \mathrm{s}$ & 80.4 & $1.99 ; \mathrm{m}$ & 43.2 \\
\hline & & & & & $1.99 ; \mathrm{m}$ & \\
\hline 2 & & 130.2 & & 129.8 & & 124.5 \\
\hline 3 & & 130.7 & & 130.6 & & 129.8 \\
\hline 4 & & 176.3 & & 176.7 & & 176.9 \\
\hline \multirow[t]{2}{*}{5} & $1.92 ; \mathrm{d} ; 4.7$ & 25.2 & $1.85 ; \mathrm{m}$ & 26.0 & $1.82 ; \mathrm{d} ; 4.5$ & 25.4 \\
\hline & $1.44 ; \mathrm{d} ; 4.3$ & & $1.40 ; \mathrm{dd} ; 7.2,10.8$ & & 1.38 ; dd; $1.0,4.5$ & \\
\hline 6 & & 31.8 & & 31.9 & & 31.6 \\
\hline 7 & & 35.9 & & 34.8 & & 34.6 \\
\hline 8 & $3.38 ; \mathrm{d} ; 9.8$ & 77.5 & $3.47 ; \mathrm{d} ; 9.5$ & 77.7 & $3.45 ; d ; 10.6$ & 78.1 \\
\hline 9 & $2.41 ; \mathrm{m}$ & 41.5 & $2.24 ; \mathrm{m}$ & 40.8 & $2.4 ; \mathrm{m}$ & 44.6 \\
\hline \multirow[t]{2}{*}{10} & $2.04 ; \mathrm{dd} ; 7.7,12.5$ & 42.6 & $1.86 ; \mathrm{m}$ & 41.4 & $1.96 ;$ dd; 4,12 & 45.7 \\
\hline & $1.23 ; \mathrm{m}$ & & $1.48 ; \mathrm{dd} ; 7.8,12.6$ & & 1.26 ; dd; 9,12 & \\
\hline 11 & & 42.3 & & 41.8 & & 38.9 \\
\hline \multirow[t]{2}{*}{12} & $5.05 ;$ ddd; $2.7,7.1,14.1$ & 68.0 & $5.28 ;$ ddd; $2.4,3.0,14.1$ & 67.9 & $4.84 ;$ ddd; $2.6,4.1,13.1$ & 68.1 \\
\hline & 4.95 ; ddd $1.6,4.7,14.1$ & & $4.96 ; \mathrm{ddd} ; 2.4,4.2,14.1$ & & $4.75 ;$ ddd; $2.0,2.8,13.1$ & \\
\hline 13 & $1.56 ; \mathrm{s}$ & 14.7 & $1.54 ; \mathrm{s}$ & 14.6 & $1.56 ; \mathrm{s}$ & 14.7 \\
\hline 14 & $1.06 ; \mathrm{s}$ & 26.5 & $0.94 ; s$ & 22.2 & $1.06 ; \mathrm{s}$ & 28.4 \\
\hline 15 & $0.94 ; \mathrm{s}$ & 20.6 & $0.95 ; \mathrm{s}$ & 26.2 & $1.02 ; \mathrm{s}$ & 29.1 \\
\hline $\mathrm{OH}$ & - & - & - & - & 1.55 & - \\
\hline
\end{tabular}

a) Sterner et al. (1990) Tetrahedron, 46, 2389-2400.

in plants. Through a screening of extracts of the culture filtrates, mycelia, and fruiting bodies of mushrooms, we found that the extract of the culture filtrate of Phlebia tremellosa (Schrad.) Nakasone \& Burds. (syn. Merulius tremellosus Schrad.) showed this activity. $P$. tremellosa is a white-rot fungus that is distributed in tropical to subarctic zones worldwide. Various isolactarane and sterpurane sesquiterpenes, such as merulidial, merulactone, and tremetriol, have been isolated from the culture filtrates of P. tremellosa. ${ }^{14-17)}$ Among them, merulidial has shown antimicrobial activity, mutagenesis activity, and cell toxicity. ${ }^{14,16,18)}$ In the present study, the compounds that promote lettuce root development were isolated from the culture filtrate of $P$. tremellosa and identified.

\section{Materials and Methods}

\section{General}

${ }^{1} \mathrm{H}$ and ${ }^{13} \mathrm{C}$ NMR spectra and 2D spectra (COSY, HMQC, and $\mathrm{HMBC}$ ) were recorded using an Avance II instrument (Bruker, Billerica, MA, USA). High-resolution mass spectra were measured using an Exactive mass spectrometer (Thermo Fisher Scientific, Waltham, MA, USA), and ESI-MS was conducted using a Quattro Micro API mass spectrometer (Waters, Milford, MA, USA) connected to an Acquity UPLC instrument (Waters). GC-MS analysis was performed using a GCMS-QP2010 Plus (Shimadzu, Kyoto, Japan) equipped with an Rtx-5MS column ( $30 \mathrm{~m} \times 0.25 \mathrm{~mm}, 0.25 \mu \mathrm{m}$ thickness, GL Sciences, Tokyo, Japan).
Preparative HPLC was performed with a 10A HPLC system (Shimadzu).

\section{Bioassay}

A single layer of filter paper was placed in the wells of a 24-well plate, and $300 \mu \mathrm{L}$ of solutions of mushroom extracts in $1 \%$ DMSO was added to the wells. The extract concentration was fixed at $250 \mu \mathrm{g} / \mathrm{mL}$. In the experiments with fractions of extracts of the culture filtrates from $P$. tremellosa, the samples were dissolved in methanol. The methanol solutions were added to the wells; methanol was removed by air-drying, and then $300 \mu \mathrm{L}$ of distilled water was added. Four lettuce (Lactuca sativa L. cv. Melbourne MT) seeds were placed in a well and incubated at $28^{\circ} \mathrm{C}$ with $16 \mathrm{hr} / 8 \mathrm{hr}$ light and dark cycles. After incubation for six days, images of the seedlings were obtained using a scanner (CanoScan LiDE 220, Canon, Tokyo, Japan), and the lengths of the primary and lateral roots and the number of lateral roots were measured using Image J (https://imagej.nih.gov/ij/docs/ install/windows.html) software.

\section{Preparation of mushroom extracts for screening}

We have made an extract library from the cultures of preserved mushroom strains in the FMRC and fruiting bodies collected from the field. The preserved mushroom strains were restored by culturing on a malt extract agar medium containing malt extract $(15 \mathrm{~g} / \mathrm{L})$ and agar $(20 \mathrm{~g} / \mathrm{L})$ in distilled water. After a $2-4$ 


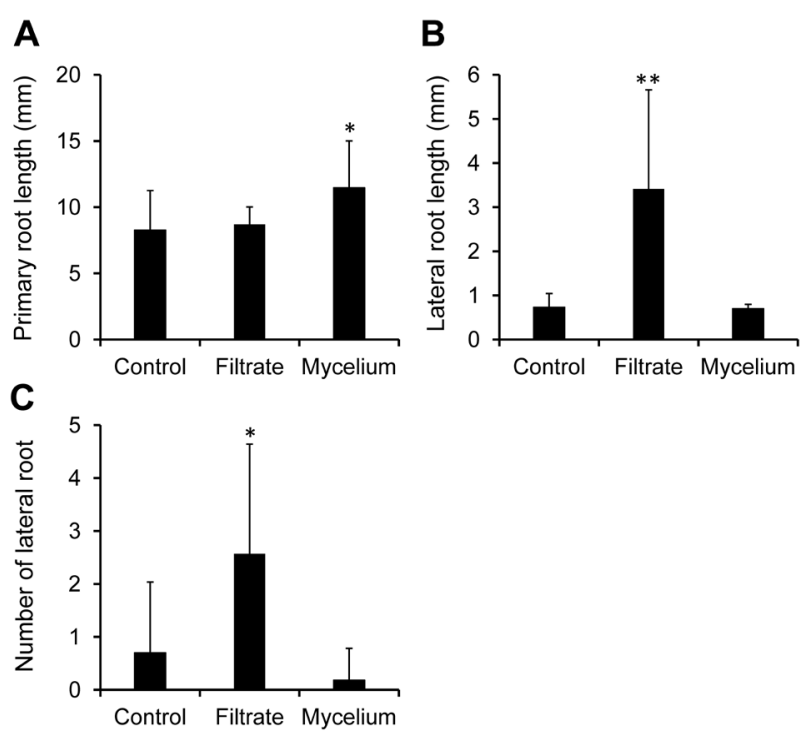

Fig. 1. Effects of treatment with extracts of the culture filtrate and mycelium of $P$. tremellosa on the growth of primary (A) and lateral (B) roots of lettuce seedlings. The lettuce seeds were sown in $250 \mu \mathrm{g} / \mathrm{mL}$ solutions of extracts of the culture filtrate and mycelium of $P$. tremellosa and incubated for six days. Data are presented as means of eight replicates. Error bars indicate standard deviations. Asterisks indicate statistically significant differences from the control $(* p<0.05, * * p<0.01$, Kruskal-Wallis test).

week incubation, the mycelia were inoculated to a malt extract liquid medium ( $200 \mathrm{~mL} /$ flask, 25 flasks) consisting of glucose $(30 \mathrm{~g} / \mathrm{L})$, peptone $(3 \mathrm{~g} / \mathrm{L})$, the extract from $50 \mathrm{~g} / \mathrm{L}$ of malt, and tap water. The cultures were further incubated for 1-3 months and separated into mycelia and culture by filtration. The mycelia were air-dried and extracted by methanol three times. The extracts were combined and evaporated as a mycelium extract. The culture filtrate was partitioned with ethyl acetate three times. The ethyl acetate layers were combined, dried over $\mathrm{Na}_{2} \mathrm{SO}_{4}$ overnight, evaporated, and used as a culture filtrate extract. The fruiting bodies obtained through a mycelial block cultivation method were freeze-dried and well powdered. The resulting powder was successively extracted using ether, dichloromethane, methanol, and water. The obtained extracts were evaporated to dryness and subjected to screening.

\section{Liquid culture of $\mathrm{P}$. tremellosa}

P. tremellosa (TUFC11737) is the preserved strain of the FMRC at Tottori University (http://fungusdb.muses.tottori-u.ac.jp/ searches/index/en). The strain was obtained from Saihaku-gun in Tottori Prefecture in Octobers 2008. The strain was cultured without shaking at $25^{\circ} \mathrm{C}$ for 47 days in the dark in $500 \mathrm{~mL}$ conical flasks containing a malt extract liquid medium $(200 \mathrm{~mL} /$ flask, 25 flasks).

\section{Purification of active compounds}

The culture filtrate $(5 \mathrm{~L})$ of $P$. tremellosa was extracted with ethyl acetate $(1.7 \mathrm{~L})$ three times. The extract was dried over $\mathrm{Na}_{2} \mathrm{SO}_{4}$ overnight and evaporated to dryness. The extract $(0.81 \mathrm{~g})$ was subjected to column chromatography using silica gel ( $85 \mathrm{~g}$, Daisogel IR-60-63/210, Daiso, Osaka, Japan). The column was eluted with mixtures of acetone and hexane. The concentration of acetone was increased from 0 to $60 \%$ in increments of $10 \%$ with the volume of each fraction being $650 \mathrm{~mL}$. Then the column was eluted with $100 \%$ acetone and washed with methanol in volumes of $650 \mathrm{~mL}$. Activity was detected in the $20 \%$ acetone fraction (324 mg).

An aliquot of the $20 \%$ acetone fraction $(289 \mathrm{mg}$ ) was subjected to silica gel column chromatography $(28.5 \mathrm{~g}$, Daisogel IR-60-63/210). The column was eluted with mixtures of ethyl acetate and hexane. The concentration of ethyl acetate was increased from 20 to $60 \%$ in increments of $10 \%$, with the volume of each mixture being $285 \mathrm{~mL}$. Activity was detected in the $50 \%$ $(17.8 \mathrm{mg})$ and $60 \%(60.8 \mathrm{mg})$ ethyl acetate fractions.

The $60 \%$ fraction was subjected to preparative TLC $\left[\mathrm{SiO}_{2}\right.$ glass plate, 60 F254 silica gel, Merck, Darmstadt, Germany; solvent, ethyl acetate- $n$-hexane $(4: 1, \mathrm{v} / \mathrm{v})]$ and divided into six fractions. Fraction 5 corresponded to the $\mathrm{UV}$-active band at $\mathrm{R}_{\mathrm{f}}$ values of $0.37-0.46$. We subjected this fraction to preparative HPLC because it was active. The HPLC conditions were as follows: column, Cosmosil 5C $18^{-}$AR-II $10 \mathrm{~mm}$ ID $\times 250 \mathrm{~mm}$ (Nacalai Tesque, Kyoto, Japan); column temperature, $40^{\circ} \mathrm{C}$; flow rate, $3 \mathrm{~mL} / \mathrm{min}$; solvent, $30 \%$ acetonitrile in water; detection, $280 \mathrm{~nm}$. The major peak was eluted at $4.01 \mathrm{~min}$. The fraction corresponding to this peak was concentrated to yield $\mathbf{1}$.

Compound 1. 5.9 mg. Positive ESI-MS m/z: $247[\mathrm{M}+\mathrm{H}]^{+}, \mathrm{HR}-$
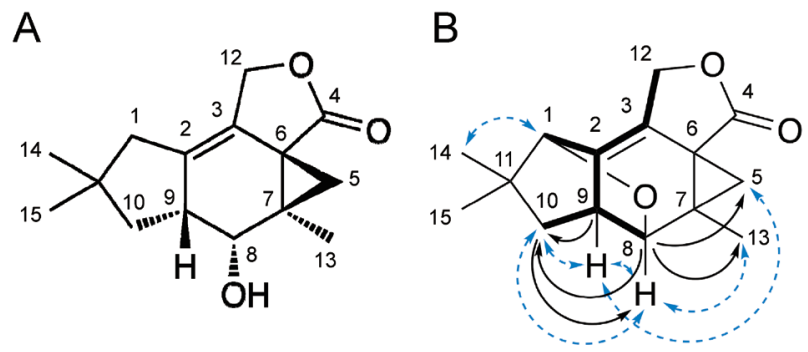

C

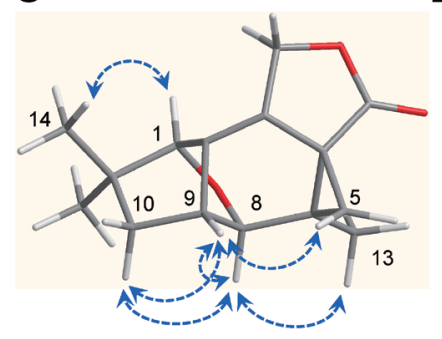

D

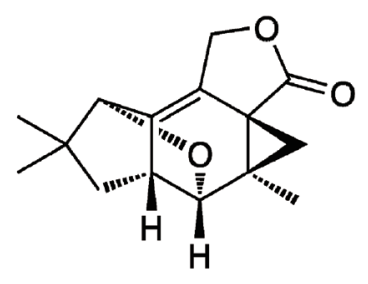

Fig. 2. Analysis of the chemical structure of 1. (A) Chemical structure of merulactone. (B) COSY (bold line), HMBC (black arrows from carbon to proton), and NOESY (blue arrows from proton to proton) correlations of 1 . HMBC correlations from C-8, C-9, and C-10 are indicated. (C) NOESY correlations on three-dimensional chemical structure of $\mathbf{1}$. (D) Chemical structure of phlelactone A. The absolute stereochemistry of $\mathbf{1}$ was not determined. The indicated structure was constructed assuming that the stereochemistry of the 6 and 7 positions was the same as that of merulactone. 
A

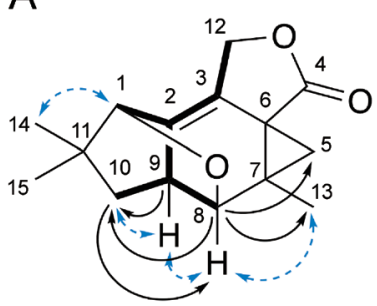

B
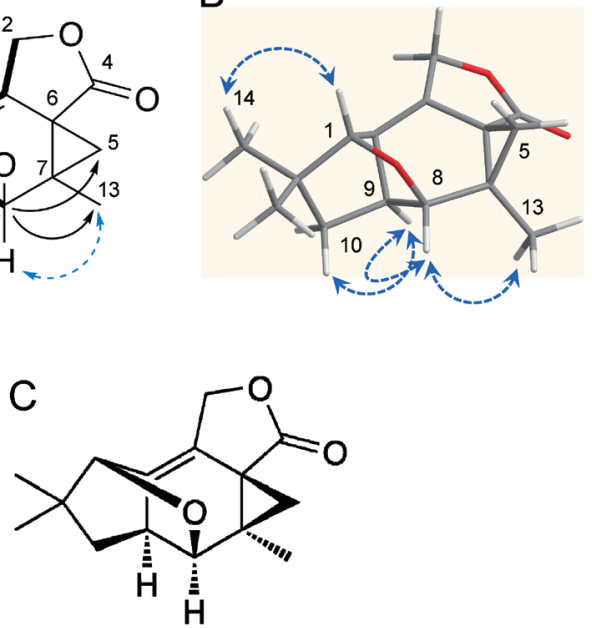

Fig. 3. Analysis of the chemical structure of 2. (A) COSY (bold line), HMBC (black arrows from carbon to proton), and NOESY (blue arrows from proton to proton) correlations of 2 . HMBC correlations from C-8, C-9, and C-10 are indicated. (B) NOESY correlations on three-dimensional chemical structure of 2. (C) Chemical structure of phlelactone B. The absolute stereochemistry of $\mathbf{2}$ was not determined. The indicated structure was constructed assuming that the stereochemistry of the 6 and 7 positions was the same as that of merulactone.

ESI-MS $m / z$ : $247.1324[\mathrm{M}+\mathrm{H}]^{+}$(calc. for $\mathrm{C}_{15} \mathrm{H}_{19} \mathrm{O}_{3}: 247.1334$ ). EI-MS (70 eV) m/z (rel. int.): $246(35)[\mathrm{M}]^{+}, 231$ (33), 217 (31), 203 (28), 189 (40), 173 (24), 159 (91), 157 (46), 145 (57), 143 (51), 131 (44), 115 (42), 105 (44), 91 (55), 77 (41), 43 (100). $\mathrm{CD} \lambda_{\max }(\Delta \varepsilon): 225(-0.030), 266(-0.025), 280(-0.026), 342$ (0.0073). NMR data are shown in Table 1 and Figs S1 and S2.

The $50 \%$ fraction $(17.8 \mathrm{mg}$ ) was subjected to preparative TLC $\left[\mathrm{SiO}_{2}\right.$ glass plate, $60 \mathrm{~F} 254$ silica gel, Merck; solvent, ethyl acetate- $n$-hexane $(4: 1, \mathrm{v} / \mathrm{v})]$ and divided into six fractions. The activity was detected in fraction 5 , which corresponded to the UVactive band at $\mathrm{R}_{\mathrm{f}}$ values of $0.40-0.51$. This fraction was subjected to preparative HPLC under the same conditions as for $\mathbf{1}$. The major peak was eluted at $4.70 \mathrm{~min}$. The fraction corresponding to this peak was concentrated to yield 2 .

Compound 2. $9.7 \mathrm{mg}$. Positive ESI-MS m/z: $247[\mathrm{M}+\mathrm{H}]^{+}$. HRESI-MS $m / z: 246.1326[\mathrm{M}+\mathrm{H}]^{+}$(Calc. for $\mathrm{C}_{15} \mathrm{H}_{19} \mathrm{O}_{3}:$ 247.1334). $\mathrm{CD} \lambda_{\max }(\Delta \varepsilon): 245(-0.022), 263(-0.019), 283(-0.021), 349$ (0.0078). EI-MS (70 eV) m/z (rel. int.): 246 (48) [M] $]^{+}, 231$ (39), 217 (75), 203 (51), 173 (72), 159 (54), 131 (54), 119 (60), 105 (76), 91 (100), 79 (58), 77 (74), 43 (90), 41 (73). NMR data are shown in Table 1 and Figs. S2 and S3.

Chemical sifts of ${ }^{1} \mathrm{H}$ and ${ }^{13} \mathrm{C}$ NMR data of $\mathbf{1}$ and $\mathbf{2}$ are summarized in Fig. S5

\section{Results and Discussion}

\section{Isolation of compounds}

We examined the root growth promotion activities of the extracts of the mycelia and culture filtrates of 33 mushrooms (Table S1) and the extracts of the fruiting bodies of 8 mushrooms (Table S2) at $250 \mu \mathrm{g} / \mathrm{mL}$. The extract of the culture filtrate and mycelium of P. tremellosa exhibited activity, as shown in Fig. 1. Treatment with the extract of the culture filtrate did not affect the length of the primary root (Fig. 1A) but did enhance the elongation of the lateral roots (Fig. 1B) and increase the number of lateral roots (Fig. 1C). On the other hand, the mycelium extract slightly enhanced the elongation of the primary root but did not affect lateral root development. Next, we cultured $P$. tremellosa on a large scale to isolate the active compounds. The filtrate of the P. tremellosa culture was extracted and subjected to activity-guided fractionation by column chromatography, TLC and HPLC. Finally, we obtained two active compounds, $\mathbf{1}$ and $\mathbf{2 .}$

\section{Determination of the chemical structures of $\mathbf{1}$ and $\mathbf{2}$}

The positive ESI-MS analyses of $\mathbf{1}$ and $\mathbf{2}$ indicated that they each had a molecular weight of 246. The respective HR-ESI-MS data for 1 and 2 showed protonated molecule peaks at $\mathrm{m} / z 247.1324$ and $m / z 247.1326$, indicating that their molecular formula were $\mathrm{C}_{15} \mathrm{H}_{18} \mathrm{O}_{3}$, and thus their hydrogen deficiency indices were 7 . Because the isolactarane sesquiterpene merulactone $\left(\mathrm{C}_{15} \mathrm{H}_{20} \mathrm{O}_{3}\right.$, M.W. 248, Fig. 1A) was previously isolated from the culture filtrate of this species, ${ }^{17)}$ we speculated that $\mathbf{1}$ and $\mathbf{2}$ may be dehy-
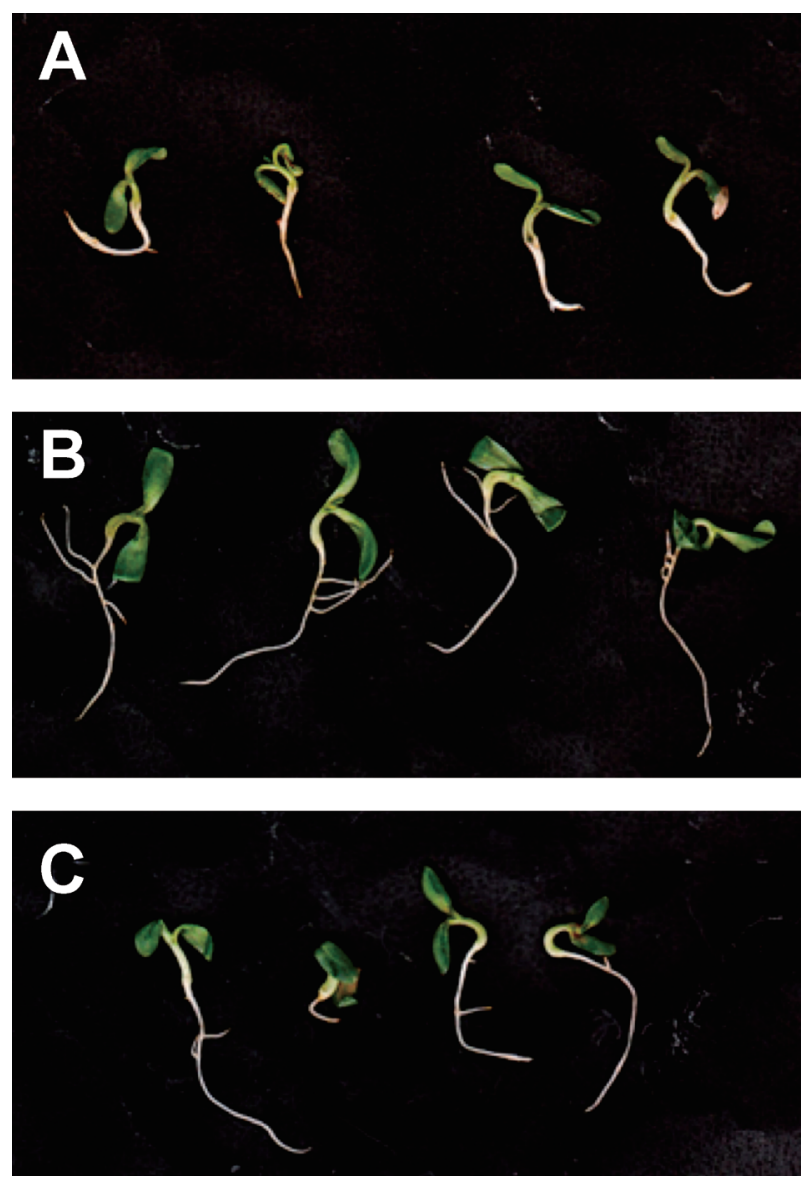

Fig. 4. Lettuce seedlings germinated in distilled water (A) and solutions of phlelactone A at $300 \mu \mathrm{g} / \mathrm{mL}$ (B) and phlelactone B at $30 \mu \mathrm{g} / \mathrm{mL}$ (C). The lettuce seeds were sown in the solutions of the phlelactones and incubated for six days. 


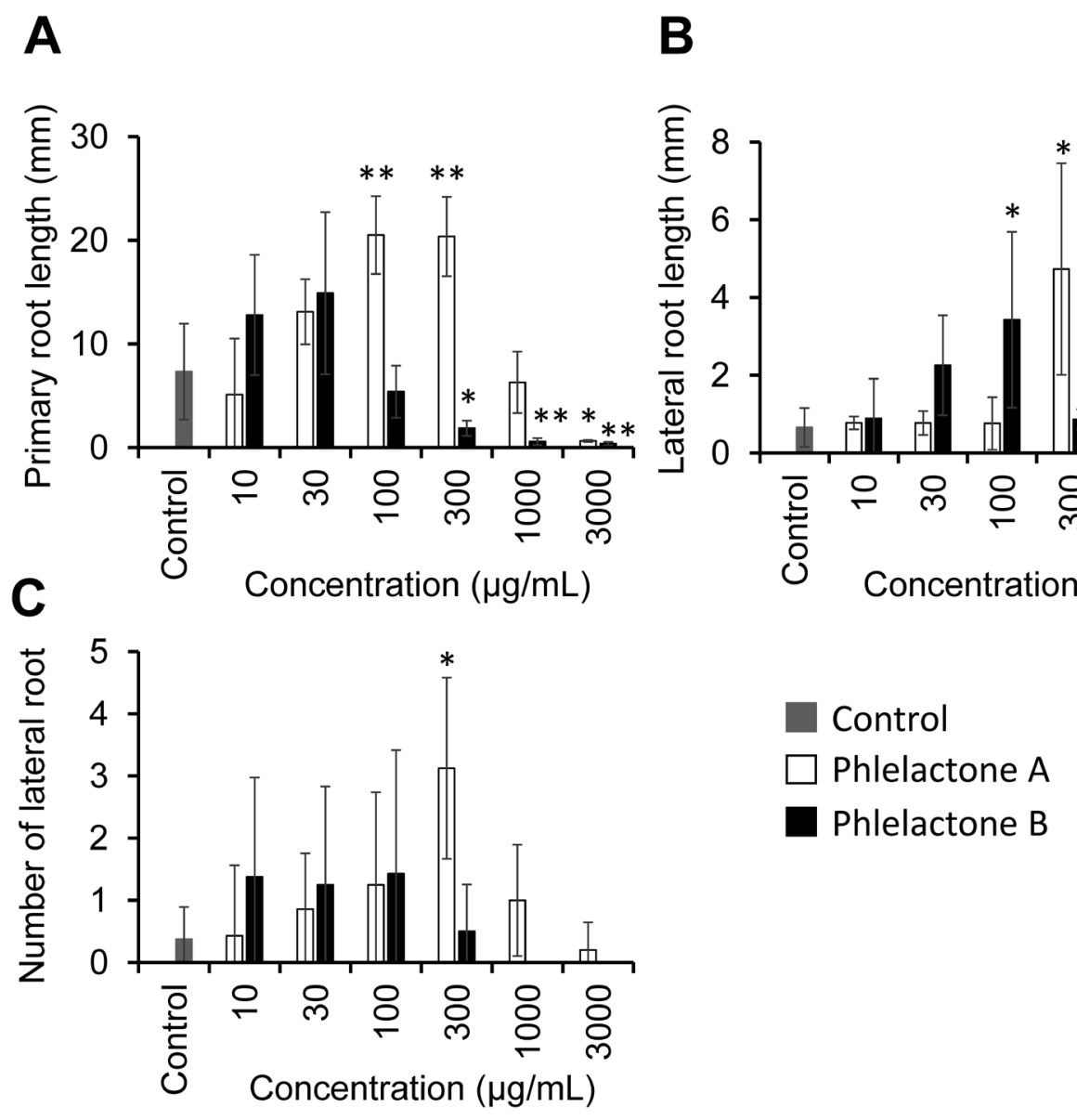

Fig. 5. Effects of treatment with phlelactones $A$ and $B$ on the growth of primary (A) and lateral (B) roots and the number of lateral roots (C). The lettuce seeds were sown in the solutions of phlelactones A (white bars) and B (black bars). As a control, the seeds were also sown in distilled water (gray bars). The lengths and numbers were recorded after a six-day incubation period. Data are presented as the means of eight replicates. Error bars indicate standard deviations. No lateral root was formed in seedlings treated with phlelactone B at 1,000 or $3,000 \mu \mathrm{g} / \mathrm{mL}$. Asterisks indicate statistically significant differences from the control $(* p<0.05, * * p<0.01$, Kruskal-Wallis test).

drogenated compounds derived from it.

A comparison of the ${ }^{13} \mathrm{C}$ NMR spectrum of 1 with that of merulactone (Table 1 ) revealed that the chemical shifts of the signals other than the signal at $\delta_{\mathrm{C}} 80.5$ of 1 were largely unchanged compared with those of merulactone. Thus, the oxygen at the 8 position is likely connected to the carbon corresponding to this signal. This carbon was assumed to be $\mathrm{C}-1$ or $\mathrm{C}-10$ because all of the other ${ }^{13} \mathrm{C}$ NMR signals were assigned on the bases of ${ }^{1} \mathrm{H}$ and ${ }^{13} \mathrm{C}$ NMR and 2D NMR. In the HMBC spectrum, the signal of C-9 at $\delta_{\mathrm{C}} 41.5$ showed correlations with the ${ }^{1} \mathrm{H}$ NMR signals at $\delta_{\mathrm{H}} 2.04$ and $\delta_{\mathrm{H}} 1.23$ (H-10) (Fig. 2B). The $\mathrm{H}-10$ protons were connected to the carbon corresponding to the signal at $\delta_{\mathrm{C}} 42.6$; hence, this signal was assigned to C-10. Accordingly, the signal at $\delta_{\mathrm{C}} 80.5$ was assigned to $\mathrm{C}-1$. Thus, we concluded that $\mathbf{1}$ is the compound in which the carbons corresponding to C-1 and C-8 in merulactone are bridged by an oxygen atom.

The relative stereochemistry of $\mathbf{1}$ was determined using its NOESY spectrum (Fig. 2B and 2C). The cross peaks of $\mathrm{H}-8 / \mathrm{H}-$ $10, \mathrm{H}-8 / \mathrm{H}-9$, and H-5/H-9 indicated that the oxygen bridge of 1 exists on the opposite side of the cyclopropane ring. As 1 has not been reported to our knowledge, we referred to $\mathbf{1}$ as phlelactone A (Fig. 2D).

A comparison of the ${ }^{1} \mathrm{H}$ and ${ }^{13} \mathrm{C}$ NMR spectra of 2 (Table 1) with those of merulactone suggested that the oxygen atom at the 8 position is connected to the carbon corresponding to the signal at $\delta_{\mathrm{C}} 80.4$, which is assigned to C- 1 or C-10, again because the chemical shifts of the other signals were similar to those of merulactone. The HMBC spectrum showed a correlation between C-9 at $\delta_{\mathrm{C}} 40.8$ and $\mathrm{H}-10$ at $\delta_{\mathrm{H}} 1.86$ and 1.48 , which are connected to the carbon corresponding to the signal at $\delta_{\mathrm{C}} 41.8$ (Fig. 3A). Thus, this carbon was identified as C-10. Accordingly, the carbon signal at $\delta_{\mathrm{C}} 80.4$ was assigned to C-1, and C- 8 and C-1 of 2 are connected by an oxygen bridge, similar to 1 .

The relative stereochemistry of $\mathbf{2}$ was determined using its NOESY spectrum (Fig. 3B and C). The spectrum showed a cross peak for H-8/H-9 but not for H-5/H-9. Thus, the oxygen bridge was considered to be present on the same side as the cyclopropane ring, as shown in Fig. 3C. This compound has not been reported to our knowledge, so we referred to 2 as phlelactone $\mathrm{B}$.

Phlelactones A and B are isomers of each other and classified 
as isolactarane sesquiterpenes. From $P$. tremellosa, isolactarane sesquiterpenes such as merulidial and merulactone, as well as a biosynthetically related sterpurane sesquiterpene, tremetriol, have been identified. ${ }^{14-17)}$ The phlelactones are likely biosynthesized via a common pathway to those of these sesquiterpenes although we cannot exclude the possibility that the phlelactones were formed from merulactone or related compounds by a nonenzymatic oxidation reaction during the long culturing period. The absolute stereochemistry of phlelactones $\mathrm{A}$ and $\mathrm{B}$ was not determined. Assuming that the stereochemistry of C-6 and C-7 of phlelactones $\mathrm{A}$ and $\mathrm{B}$ are the same as those of merulactone, the stereochemistry at C-8 of phlelactone $\mathrm{A}$ is the same as that of merulactone, but that of phlelactone $\mathrm{B}$ is different. No compound with the same stereochemistry at that at C- 8 of phlelactone B has been found in P. tremellosa.

\section{Growth promotion effects of phlelactones $A$ and $B$ on primary and lateral lettuce roots}

As shown in Fig. 4, both phlelactones A and B showed promoting effects on the development of lettuce roots. Phlelactone A enhanced primary root growth at 100 and $300 \mu \mathrm{g} / \mathrm{mL}$ with approximately 2.8 -fold increases, while it inhibited root elongation almost completely at $3,000 \mu \mathrm{g} / \mathrm{mL}$ (Fig. 5A). The compound promoted the elongation and generation of lateral roots at $300 \mu \mathrm{g} /$ $\mathrm{mL}$ but was inhibitory at higher concentrations (Fig. 5B). Phlelactone $\mathrm{B}$ promoted primary root elongation at lower concentrations than phlelactone A (Fig. 5A). At higher concentrations, phlelactone $\mathrm{B}$ also inhibited primary root elongation. The most effective concentration of phlelactone $B$ for the elongation of lateral roots was $100 \mu \mathrm{g} / \mathrm{mL}$ (Fig. 5B). Treatments with phlelactones $\mathrm{A}$ and $\mathrm{B}$ tended to increase the number of lateral roots at the lower concentrations, although the effect was statistically significant only at $300 \mu \mathrm{g} / \mathrm{mL}$ of phlelactone A.

The crude extract of the P. tremellosa culture filtrate showed promotion activity on root development at $250 \mu \mathrm{g} / \mathrm{mL}$. Pure phlelactones A and B showed the marked activity at 100-300 $\mu \mathrm{g} /$ $\mathrm{mL}$. Thus, the activity in the crude extract could not be accounted for by phlelactones A and B alone; other active compounds may be present in the extract.

The initiation and development of roots are controlled by various endogenous signals. ${ }^{19)}$ Auxin is known to be the central player that controls root development. A high level of auxin induces lateral root growth and represses primary root elongation. Lateral roots are more sensitive than primary roots to exogenously applied auxin. ${ }^{20)}$ Along with auxin, cytokinin ${ }^{21,22)}$ and abscisic acid ${ }^{23,24)}$ affect root development. Recently, the mode of action of isoprothiolane, which shows root growth promotion effects on plants, was analyzed in Arabidopsis by using plant hormone-related mutants and chemical inhibitors of plant hormones. ${ }^{25)}$ The analysis showed the involvement of auxin, jasmonic acid, and ethylene in the root growth promotion by isoprothiolane. To determine the mode of action of the phlelactones, it is important to investigate their effects on the hormonal control of root development.

\section{Acknowledgements}

We thank Ms. Mizuki Yokono, Technical Department, Tottori University, for her assistance with HR-ESI-MS. We also thank Dr. Shinichi Yoshida, Tottori Institute for Industrial Technology, for his assistance with EI-MS.

\section{References}

1) W. Rademacher: J. Plant Growth Regul. 34, 845-872 (2015).

2) R. Bulgari, G. Cocetta, A. Trivellini, P. Vernieri and A. Ferrante: Biol. Agric. Hortic. 31, 1-17 (2015).

3) S. Nishino, R. Y. Parada, T. Ichiyanagi, N. Maekawa, N. Shimomura and H. Otani: J. Phytopathol. 161, 515-521 (2013).

4) K. Oka, A. Ishihara, N. Sakaguchi, S. Nishino, R. Y. Parada, A. Nakagiri and H. Otani: J. Phytopathol. 163, 987-996 (2015).

5) A. Ishihara, Y. Ide, T. Bito, N. Ube, N. Endo, K. Sotome, N. Maekawa, K. Ueno and A. Nakagiri: Biosci. Biotechnol. Biochem. 82, 22-30 (2018).

6) H. Evershed: Nature 29, 384-385 (1884).

7) J. H. Choi, K. Fushimi, N. Abe, H. Tanaka, S. Maeda, A. Morita, M. Hara, M. Hara, R. Motohashi, J. Matsunaga, Y. Eguchi, N. Ishigaki, D. Hashizume, H. Koshino and H. Kawagishi: ChemBioChem 11, 13731377 (2010).

8) J. H. Choi, N. Abe, H. Tanaka, K. Fushimi, Y. Nishina, A. Morita, Y. Kiriiwa, R. Motohashi, D. Hashizume, H. Koshino and H. Kawagishi: J. Agric. Food Chem. 58, 9956-9959 (2010).

9) A. Mitchinson: Nature 505, 298 (2014).

10) T. Asai, J. H. Choi, T. Ikka, K. Fushimi, N. Abe, H. Tanaka, Y. Yamakawa, H. Kobori, Y. Kiriiwa, R. Motohashi, V. K. Deo, T. Asakawa, T. Kan, A. Morita and H. Kawagishi: Jpn. Agric. Res. Q. 49, 45-49 (2015).

11) H. Tobina, J. H. Choi, T. Asai, Y. Kiriiwa, Y. Asakawa, T. Kan, A. Morita and H. Kawagishi: Field Crops Res. 162, 6-11 (2014).

12) M. Ogawa and Y. Ohta: Proc. Crop Sci. Soc. Jpn. 42, 499-505 (1973).

13) T. Ohtsuka and H. Saka: Jpn. J. Crop. Sci. 56, 571-576 (1987).

14) M. G. Bruno and B. Steffan: Terahedron 42, 3579-3586 (1986).

15) M. Jonassohn, H. Anke, O. Sterner and C. Svensson: Tetrahedron Lett. 35, 1593-1596 (1994).

16) W. Quack, T. Anke, O. Oberwinkler, M. G. Giannetti and W. Steglich: Antibiotics (Basel) 31, 737-741 (1978).

17) O. Sterner, T. Anke, W. Sheldrick and W. Steglich: Tetrahedron 46, 2389-2400 (1990).

18) H. Anke, O. Sterner and W. Steglich: J. Antibiot. (Tokyo) 42, 738-744 (1989).

19) H. Tian, I. De Smet and Z. Ding: Trends Plant Sci. 7, 426-431 (2014).

20) Z. Ding and J. Friml: Proc. Natl. Acad. Sci. U.S.A. 107, 12046-12051 (2010).

21) B. Muller and J. Sheen: Nature 453, 1094-1097 (2008).

22) A. Bielach, K. Podlešáková, P. Marhavý, J. Duclercq, C. Cuesta, B. Müller, W. Grunewald, P. Tarkowski and E. Benková: Plant Cell 24, 3967-3981 (2012).

23) I. De Smet, L. Signora, T. Beeckman, D. Inzé, C. H. Foyer and H. Zhang: Plant J. 33, 543-555 (2003).

24) H. Zhang, W. Han, I. De Smet, P. Talboys, R. Loya, A. Hassan, H. Rong, G. Jürgens and J. P. Knox: Plant J. 64, 764-774 (2010).

25) M. Kusajima, M. Nagata, N. Miyashita, Y. Yotagakiuchi, K. Maehara, I. Miyazaki, M. Inoue, M. Fujita and H. Nakashita: J. Pest Sci. 43, 186-190 (2018). 